\title{
Research of Teaching Behaviors in Smart Classroom Supported by Interactive Media
}

\author{
ZHU Jiahua \\ School of Teacher Education \\ Central China Normal University \\ Wu Han, PRC \\ YANG Hongli \\ School of Life Sciences \\ Central China Normal University \\ Wu Han, PRC
}

\author{
BA Hezhen \\ School of Life Sciences \\ Central China Normal University \\ Wu Han, PRC \\ ZHANG Xiuhong \\ School of Life Sciences \\ Central China Normal University \\ Wu Han, PRC
}

\author{
CUI Hong * \\ School of Life Sciences \\ Central China Normal University \\ Wu Han, PRC \\ *Corresponding Author
}

\begin{abstract}
The smart classroom with the support of interactive media can effectively integrate resources, reshape the ecological environment of teaching and optimize classroom teaching and learning. New changes occur to the learning features and learning organization of the interactive mediasupported smart classroom when compared with the traditional multimedia classroom. In this paper, by video recording of classroom instructions, a comparison is made between the smart classroom teaching supported by interactive media and the traditional multimedia classroom teaching, applying the methods of interactive analysis and S-T analysis, utilizing Nvivo software to assist recording. The results show that, in comparison with the traditional multimedia classroom, the smart classroom supported by interactive media is more learner-centric and thus being conducive to students' subjectivity and make their participation in learning activities more abundant and deeper.
\end{abstract}

Keywords-interactive media; smart classroom; teaching behavior; classroom observation

\section{INTRODUCTION}

Smart classroom is a new type of classroom which can optimize teaching content presentation, be convenient for access to learning resources, and promote classroom interaction development, with context awareness and environment management function. It is the high end form of network classroom $^{[1]}$. The emergence of smart classroom brings about the transition from traditional digital learning environment to smart learning environment, which does not solely change the technical environment, but integrate physical, technical and emotional environments. This learning environment is characterized by strong interaction, decentralization and openness; recording of learning process, recognition of learning situation, linking of learning community and perception of physical environment become important environmental features ${ }^{[2]}$. Smart classroom satisfies the need of digital natives. In particular, the design of smart classroom adequately reflect good interactions between people and between human and technology ${ }^{[3]}$.

Interactive media refers to those media used in the classroom teaching and learning and based on digital technology, which can integrate teaching information by words and display, encode signals and respond to agent's operation, secondarily blend teaching information and inspire learners' knowledge acquisition or change of thinking. Among the pieces of technology that can support smart classroom, the most widely used interactive media include interactive whiteboards, interactive mobile devices (tablets and smartphones, etc.) and interactive learning platforms (such as cloud classroom and various learning apps).

The wide application of interactive media in building the learning space, teaching tools and resource platforms for smart classroom can develop a more harmonious synergy of teachers and students in this open and diversified smart environment and effectively promote the information revolution in teaching and learning. It can not only actively integrate and optimize traditional classroom teaching, but also by creating diversified and integrated resources and environment, innovate teaching strategy, reshape the ecological environment of teaching and solve the problems of low efficiency in configuration of educational resources and environment, unmotivated awareness and ability of students for autonomous learning. However, compared with traditional multimedia classroom, what are the characteristics of teaching behaviors in the smart classroom supported by interactive media? How can the teaching be effectively implemented in such a smart classroom? Based on 
the classroom observation, by improving or perfecting existing quantitative classroom observation tools, we make a comparative analysis of interactive and independent behaviors of teachers and students in the traditional multimedia environment and the interactive media-supported smart classroom environment. This research attempts to provide ideas and reference for innovating teaching and learning in the smart learning environment.

\section{LITERATURE REVIEW}

Teaching activity is constituted by a series of teaching and learning behaviors. From the perspective of actors, it is a behavioral system of teacher's and students' behaviors ${ }^{[4]}$. In terms of the implementers, teaching behaviors can be statically divided into teacher's behaviors, students' behaviors and teacher-student interactive behaviors ${ }^{[5]}$.

International researches of classroom teaching behaviors were primarily based on the analysis of classroom teaching. The analysis was carried out and the conclusions were reached through quantitative observations of teaching behaviors in time and space. Then, a system of accurate measurement techniques including questionnaire, scale and index design was shaped so as to gradually achieve accurate researches on classroom teaching. Currently the classical analysis approaches of classroom teaching include S-T analysis, Flanders Interaction Analysis System (FIAS) and Information Technology-based Interaction Analysis System (ITIAS). The research performed by $\mathrm{Mu} \mathrm{Su}$ et al. (2015) compared the advantages and disadvantages of these three analysis methods, as shown in Table $1^{[6]}$.

TABLE I. ADVANT AGES AND DISADVANT AGES OF TEACHING BEHAVIOR ANALYSIS METHODS

\begin{tabular}{|c|c|c|}
\hline $\begin{array}{l}\text { Analysis } \\
\text { Methods }\end{array}$ & Advantages & Disadvantages \\
\hline FIAS & $\begin{array}{l}\text { Quantifying verbal interaction } \\
\text { behaviors between teachers and } \\
\text { students for statistical and analytical } \\
\text { processing; based on quantitative data, } \\
\text { teachers can make an analysis and } \\
\text { rethinking of teaching }\end{array}$ & $\begin{array}{l}\text { Disregarding students' behavior } \\
\text { performance; being unable to } \\
\text { reflect information technology; } \\
\text { summarizing meaningful } \\
\text { nonverbal teaching behaviors } \\
\text { simply as silence } \\
\end{array}$ \\
\hline $\begin{array}{c}\mathrm{S}-\mathrm{T} \\
\text { analys is }\end{array}$ & $\begin{array}{l}\text { Data analys is only at the two } \\
\text { dimensions of teacher's and non- } \\
\text { teacher's behaviors, thus reducing } \\
\text { ambiguity of behavior classification } \\
\text { and increasing objectivity and } \\
\text { accuracy; no complexcalculations, } \\
\text { conducive to practical application }\end{array}$ & $\begin{array}{l}\text { Data type too simple, unable to } \\
\text { reflect the entire teaching process }\end{array}$ \\
\hline ITIAS & $\begin{array}{l}\text { Adding student language and } \\
\text { technology categories to FIAS }\end{array}$ & $\begin{array}{c}\text { No explanation of which } \\
\text { technology and equipment to } \\
\text { choose and how to operate by } \\
\text { teachers and students; problems of } \\
\text { cross behaviors and fuzzy } \\
\text { classification } \\
\end{array}$ \\
\hline
\end{tabular}

In the smart learning environment, profound changes have taken place in teaching behavior type and implementation. Utilizing the above three analysis approaches for teaching behaviors as the theoretical underpinnings, many researches were conducted in China on the design and application of teaching behavior analysis tools in the smart learning environment. Mu Su et al. (2015) proposed a TBAS (Teaching Behavior Analysis System), which categorized classroom teaching to be teacher's activities, students' activities and meaningless teaching activities ${ }^{[7]}$. Han Hou et al. (2015), by reference to the ITIAS, put forward an OOTIAS (One-to-One Techno-Based Interaction Analysis System) containing 24 codes in a 1:1 digital environment. Based on the qualitative research methods, the roles of interactions between people and technology in teaching were divided as "direct roles" and "indirect roles" ${ }^{[8]}$. Wang Xiaochen et al. (2015 \& 2016) proposed CIOSM (Classroom Interaction in Smart Classroom) tools and highlighted observation and analysis of actors, content, technology support, depth, feedback and participation in classroom interactions in the smart environment ${ }^{[9][10]}$. Zhang Yi et al. (2016) adapted the smart classroom interaction analysis based on the FIAS and made an analysis of interactions in mathematics classroom teaching of primary schools ${ }^{[11]}$. Chen Di (2012) provided a complete explanation of classroom teaching behavior analysis tools under the support of interactive media. By combining the advantages of FIAS and ITIAS, from the perspective of "teacher-guided and studentcentered" in class teaching, the research constructed the classroom interaction from two aspects: the first agent and the second agent, with reference to the "drive and initiative" concept in Flanders' verbal behavior categorization. This not only played down the roles of teachers and students (which could be temporarily converted in an interactive media environment), but also strengthened mutual interactions when technology facilitated teaching interactions ${ }^{[12]}$.

Teaching behaviors could be composed of three categories: teachers' behaviors, students' behaviors and teacher-student interaction behaviors. On this basis, this research divided teaching behaviors in the interactive media-supported smart classroom into two kinds: interactive behaviors between teachers and students and independent behaviors. Then, an analysis is conducted with reference to previous researches.

\section{RESEARCH DESIGN}

As described above, the interactive media-supported smart classroom teaching behaviors were divided into two types: interactive behaviors between teachers and students and independent behaviors. Based on FIAS and ITIAS, the research of interactive behaviors was carried out with reference to the research framework of Chen Di (2012). The research of independent behaviors adopted the S-T analysis method, referred to the "teacher-student behavior checklist" of Ye Lijun (2011) ${ }^{[13]}$ and used Nvivo software to assist recording and analysis.

The required course of Biological Science students, Middle School Biology Teaching Design, was selected for the research. By setting a number of comparison groups, this research compared the smart classroom environment supported by interactive media and the traditional multimedia classroom environment. The main tools of interactive media to support the materialization technologies of smart classroom include interactive whiteboards, interactive tablets and interactive learning platforms. The tools above are based on digital technology, integrate teaching information by words and display, encode signals and respond to agent's operation, secondarily blend teaching information and inspire learners' knowledge acquisition or change of thinking. 
The method of video recording was used in this research. It was carried out through the following procedures: a. lessons taking; b. video recording of class teaching; c. rough processing of teaching videos (combining videos recording teachers' and students' behaviors and removing of irrelevant clips); d. selecting samples; e. preparing behavior encoding table and deciding sampling and recording rules; f. sampling records by using the encoding table; g. statistics collection; and $h$. discussion and analysis of results.

\section{RESEARCH AND DisCUSSION ON INTERACTIVE BEHAVIORS in SMart ClassRoom Supported by INTERACTIVE MEDIA}

\section{A. Selection of Research Subjects}

In the research, four class hours were selected, including the smart classroom supported by interactive media and the traditional multimedia classroom. The detailed information of the selected classes was shown in Table 2 .
TABLE II. RESEARCH SUBJECTS OF INTERACT IVE BEHAVIORS

\begin{tabular}{|c|c|c|c|}
\hline No. & Teaching Content & Duration & $\begin{array}{l}\text { Interactive Media } \\
\text { Environment }\end{array}$ \\
\hline 1 & $\begin{array}{l}\text { Teaching design based on the } \\
\text { strategy of science his tory }\end{array}$ & $43 \mathrm{~min}$ & smart classroom \\
\hline 2 & $\begin{array}{l}\text { Teaching design based on the } \\
\text { strategy of PBL }\end{array}$ & $45 \mathrm{~min}$ & $\begin{array}{l}\text { traditional multimedia } \\
\text { classroom }\end{array}$ \\
\hline 3 & $\begin{array}{l}\text { Teaching design based on the } \\
\text { strategy of inquiry-based learning }\end{array}$ & $45 \mathrm{~min}$ & smart classroom \\
\hline 4 & $\begin{array}{l}\text { An overview of middle school } \\
\text { biology education evaluation }\end{array}$ & 48min & $\begin{array}{l}\text { traditional multimedia } \\
\text { classroom }\end{array}$ \\
\hline
\end{tabular}

\section{B. Design and Application of Tools}

Based on the FIAS and the ITIAS, with reference to the research of Chen Di (2012) mentioned above, this research constructed classroom interactive behaviors with the first agent (FA, the driver of the behavior) and the second agent (SA, the responder of the behavior) and designed the interactive behavior coding table (Table 3 ) and the interactive behavior sampling record table (Table 4).

TABLE III. INTERACTIVE BEHAVIOR CODING TABLE

\begin{tabular}{|c|c|c|c|}
\hline Subcategory & Code & Teaching Behavior Strategy & Operational Description of Teaching Behaviors \\
\hline \multirow{9}{*}{ Information Interaction } & 1 & Accept & Accept the attitude or emotional inclination of other communities in a peaceful manner \\
\hline & 2 & Praise or encourage & Praise or encourage the behaviors or manners of others \\
\hline & 3 & Adopt ideas & $\begin{array}{l}\text { Acknowledge, contrast, refine, summarize, or repeat what others say and apply it to solve } \\
\text { problems }\end{array}$ \\
\hline & 4 & Question & $\begin{array}{l}\text { Based on the opinions of the first agent, ask others questions and look forward to the } \\
\text { reply }\end{array}$ \\
\hline & 5 & Teach & $\begin{array}{l}\text { Provide facts or insights about the contents or procedures. Express the concepts and } \\
\text { directions of the first agent, or quote an authoritative opinion to draw the conclusion }\end{array}$ \\
\hline & 6 & Indicate & Instruct others to do something by using words and expect them to complete it \\
\hline & 7 & Criticize & $\begin{array}{l}\text { Expect to change others' behaviors by criticizing them and exclaim the reasons of one's } \\
\text { own behaviors. Do the self-check and reference }\end{array}$ \\
\hline & 8 & Discuss, Debate & Equally exchange views in a peaceful or competitive way \\
\hline & 9 & Respond passively & Give answers to others' questions with no deep thinking \\
\hline \multirow{3}{*}{ Concept Interaction } & 10 & Respond actively & Give answers to others' questions with deep thinking and have their own views \\
\hline & 11 & Think independently & The class is in a state of silence but participants are thinking or digesting the information \\
\hline & 12 & Complete tasks collaboratively & $\begin{array}{l}\text { Participants work together to complete tasks around thematic activities in a state of } \\
\text { confusion }\end{array}$ \\
\hline \multirow{2}{*}{$\begin{array}{l}\text { Concept Interaction } \\
\text { Environment }\end{array}$} & 13 & $\begin{array}{l}\text { Use technology to complete practice } \\
\text { and results }\end{array}$ & Use technology to calculate, produce and process content information achievement \\
\hline & 14 & $\begin{array}{l}\text { Use technology to give feedback on } \\
\text { evaluations }\end{array}$ & Use the feedback systemto initiate the evaluation activity and get feedback results \\
\hline \multirow{2}{*}{$\begin{array}{l}\text { Information } \quad \text { Interaction } \\
\text { Environment }\end{array}$} & 15 & $\begin{array}{l}\text { Use technology to exhibit contents } \\
\text { or results }\end{array}$ & $\begin{array}{l}\text { Use the interactive whiteboard or the tablet to exhibit intellectual contents or learning } \\
\text { achievement }\end{array}$ \\
\hline & 16 & $\begin{array}{l}\text { Use technology to search, arrange } \\
\text { and transmit the resource }\end{array}$ & $\begin{array}{l}\text { Use digital learning terminals, network and its software tools to search and arrange the } \\
\text { resource; transmit and share the data }\end{array}$ \\
\hline Silence and Confusion & 17 & \begin{tabular}{|l|} 
A state of confusion that has no \\
help in the teaching
\end{tabular} & The class is in a state of confusion with no behaviors related to learning or teaching \\
\hline
\end{tabular}

TABLE IV. INTERACTIVE BEHAVIOR SAMPLING RECORD TABLE

\begin{tabular}{|l|c|c|c|c|c|c|}
\hline \multirow{2}{*}{ Start Time } & \multicolumn{3}{|c|}{ FA (driver of the behavior) } & \multicolumn{2}{c|}{ SA (responder of the behavior) } \\
\cline { 2 - 6 } & Role Group & Description of Behaviors & Behavior Coding & Role Group & Description of Behaviors & Behavior Coding \\
\hline 00:00 & & & & & & \\
\hline $00: 30$ & & & & & \\
\hline
\end{tabular}

In view of the relatively slow teaching place in the university, the actual sampling was encoded and recorded in unit of 30 seconds to meet analysis needs and reduce error. The results were filled in the record table. To ensure the reliability and validity of sampling observation, two or more persons were arranged in a group for taking samples, observing and recording each class. Prior to analysis, they had discussions and consultations over the behavior code record and after analysis, they probed into any doubt and reached consensus.

Given the complexity of classroom teaching, based on coding rules of the Flanders interaction analysis, we further proposed the following coding rules ${ }^{[14][15]}$ :

- If there are a variety of verbal behaviors in 30 seconds, record them all; 
TABLE VI. INTERACTIVE BEHAVIOR ANALYSIS MATRIX OF CLASS 2

- The behavior that a teacher repeats the student's correct answer belongs to Category 2;

- The behavior that a teacher calls one student's name belongs to Category 4;

- If it is not sure which two or more categories a verbal behavior belongs to, then choose a category that is far away from Category 5, but not choose Category 17;

- If the teacher makes jokes with students not in a mockery attitude, then the behavior belongs to Category 2; otherwise, it belongs to Category 7;

- If it is not sure which category a verbal behavior belongs to, then classify it to Category 1 ;

- If the teacher only uses media to display text, it cannot be classified to Categories 13-16;

- If students only look at text on the screen, it cannot be classified to Categories 13-14;

- Each behavior agent cannot be encoded into more than 2 codes in 20 seconds. The first agent must have and only have one code.

\section{Results and Discussion}

Through encoding the samples of class teaching, each class obtained the code sequences of interactive behaviors of the first agent (FA) and the second agent (SA). The code sequence of FA was combined with that of SA to form sequence pairs. Each sequence pair was composed of: (the code sequence of FA, the corresponding code sequence of SA). The following sequence pairs may be formed by recording according to the above "interactive behavior sampling record table”.

The corresponding behavior codes of FA and SA constituted rows and columns of the matrix diagram, respectively. This research counted the frequency of sequence pairs and filled it in the matrix to get Table 5 and Table 6 (only presenting the analysis matrixes of Class 1 and 2).

TABLE V. INTERACTIVE BEHAVIOR ANALYSIS MATRIX OF CLASS 1

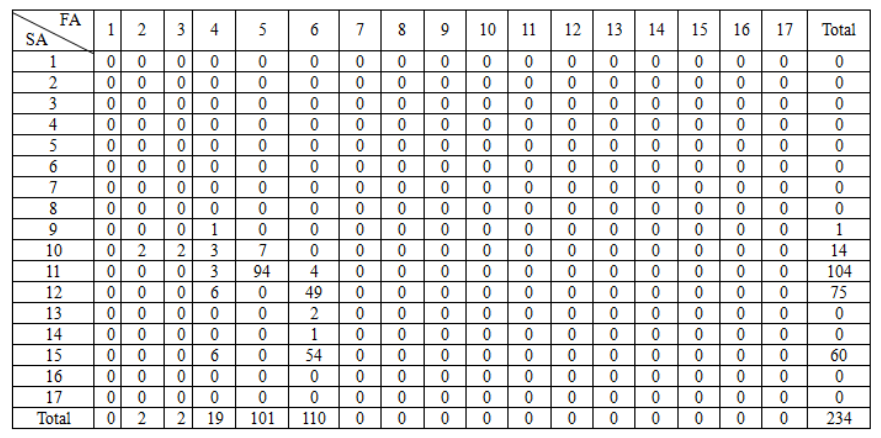

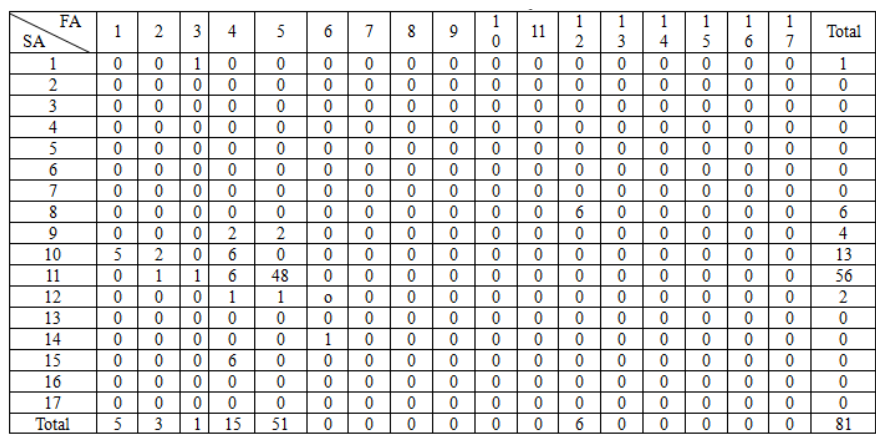

As indicated above, the total number of interactive behaviors in Class 1 (smart classroom) was 234 times. The interactive behavior of "teacher teaching-students thinking independently” occurred most frequently in 94 times; followed by the frequency of 54 times for the occurrence of the behavior "teacher questioning-students using technology to exhibit contents or achievements", 49 times for the behavior "teacher teaching-students completing tasks collaboratively", and 6 times for the behaviors "teacher questioning-students completing tasks collaboratively" and "teacher questioningstudents using technology to exhibit contents or achievements" each. While in Class 2 (traditional multimedia classroom), the total number of interactive behaviors was 81 times. The behavior "teacher teaching-students thinking independently" occurred most frequently in 48 times; followed by the frequency of 6 times for the occurrence of the behaviors "teacher questioning-students responding actively", "teacher questioning-students thinking independently" and "steacher completing tasks collaboratively-students discussing”, and 5 times for the behavior "teacher accepting-students responding actively”.

The following findings could result from the integrated research results. First, of interactive behaviors in the four classes, "teacher teaching-students thinking independently" occurred most frequently. Second, the behaviors of the teacher as the first agent (FA) belonged to the information interaction, including primarily "question", "teach" and "indicate”. Those behaviors, like "accept”, "praise or encourage”, "adopt ideas” also frequently occurred. And the behavior "concept interaction-complete tasks collaboratively" happened occasionally. Third, the behaviors of students as the second agent (SA) belonged to the concept interaction, including primarily "think independently", "respond actively" and "complete tasks collaboratively". Those behaviors, such as "discuss" and "respond passively" also frequently took place. And the behaviors of "concept-environment interaction" and "information-environment interaction" happened occasionally. Fourth, the overall distribution of the matrix was relatively concentrated. For example, when the teacher had the behavior "teach", students mostly "think independently". The emergence of interactive behaviors was characterized by continuity and aggregation in time.

Through a comparative analysis of the smart classroom supported by interactive media and the traditional multimedia classroom, the research revealed that in the smart classroom, if ignoring the influence of different teaching styles of teachers, 
the behavior of "teacher teaching-students thinking independently" occurred significantly more than that in the traditional multimedia classroom. The behaviors of teacher as the first agent belonged to the information interaction, including primarily "question", "teacher" and "indicate", and the behaviors of students as the second agent belonged to the concept interaction, including primarily "think independently", "respond actively" and "complete tasks collaboratively". Moreover, learners' behaviors of "concept-environment interaction" and "information-environment interaction" in Class 1 equipped with interactive media were significantly more than those in Class 2 without interactive media.

As a result, the interactive media provide convenience for learners' diversified learning. The teacher-student interaction enables more in-depth and effective learning. To put it simply, this achieves the interaction-based transition from shallow learning to deep learning. Teachers often "teach” and their role of teaching cannot be disregarded in the light of restrictions of theoretical nature and content difficulty of the course. Learners mostly "think independently" and this reflects that they can solve problems by different ways of thinking, methods and skills when faced with different situations. Meanwhile, different teaching environment and interactive behavior strategies have a great influence on the composition and form of teaching interaction in the class teaching. Therefore, the form of interaction must be designed with consideration to the characteristics of the teaching environment and specific strategies when we are designing teaching interaction activity.
V. RESEARCh AND DisCusSion on S-T BeHAVIORS IN SMART ClassRoOm Supported by INTERACTIVE MEdiA

\section{A. Selection of Research Subject}

The research of S-T behaviors in the smart classroom supported by interactive media was carried out by using Nvivo software and based on the observation of teacher-student behaviors in the classroom. This research extracted the class teaching fragment of "Teaching Design by the Strategy of Creating Situation”, which is the second section of Chapter 5 in the course Middle School Biology Teaching Design. The length of this fragment was 24 minutes. The teaching fragment was completed in a smart classroom supported by interactive media.

\section{B. Design and Application of Tools}

In his "research of classroom teaching behaviors of mathematics teachers", Ye Lijun (2011) pointed out that questioning, teaching language, feedback and waiting are four high-frequency behaviors in teachers' class teaching and had a very important influence on teaching effects ${ }^{[16]}$. The "behavior checklist” proposed in this research adapted the teacherstudent behavior analysis table of Ye Lijun (2011). Considering the analysis needs for teachers' operational behaviors and student-media interaction behaviors in the interactive media environment, 28 kinds of behaviors were defined and encoded from teachers' response behaviors, verbal behaviors, operational behaviors and waiting behaviors to students' response to teachers' behaviors. In the actual sampling recording, Nvivo8 software was used to achieve the input, coding and qualitative analysis of non-text data.

\section{Results and Discussion}

The analysis and behavior records of the teaching fragments were listed in Table 7 below.

TABLE VII. BEHAVIOR STATISTICS LIST

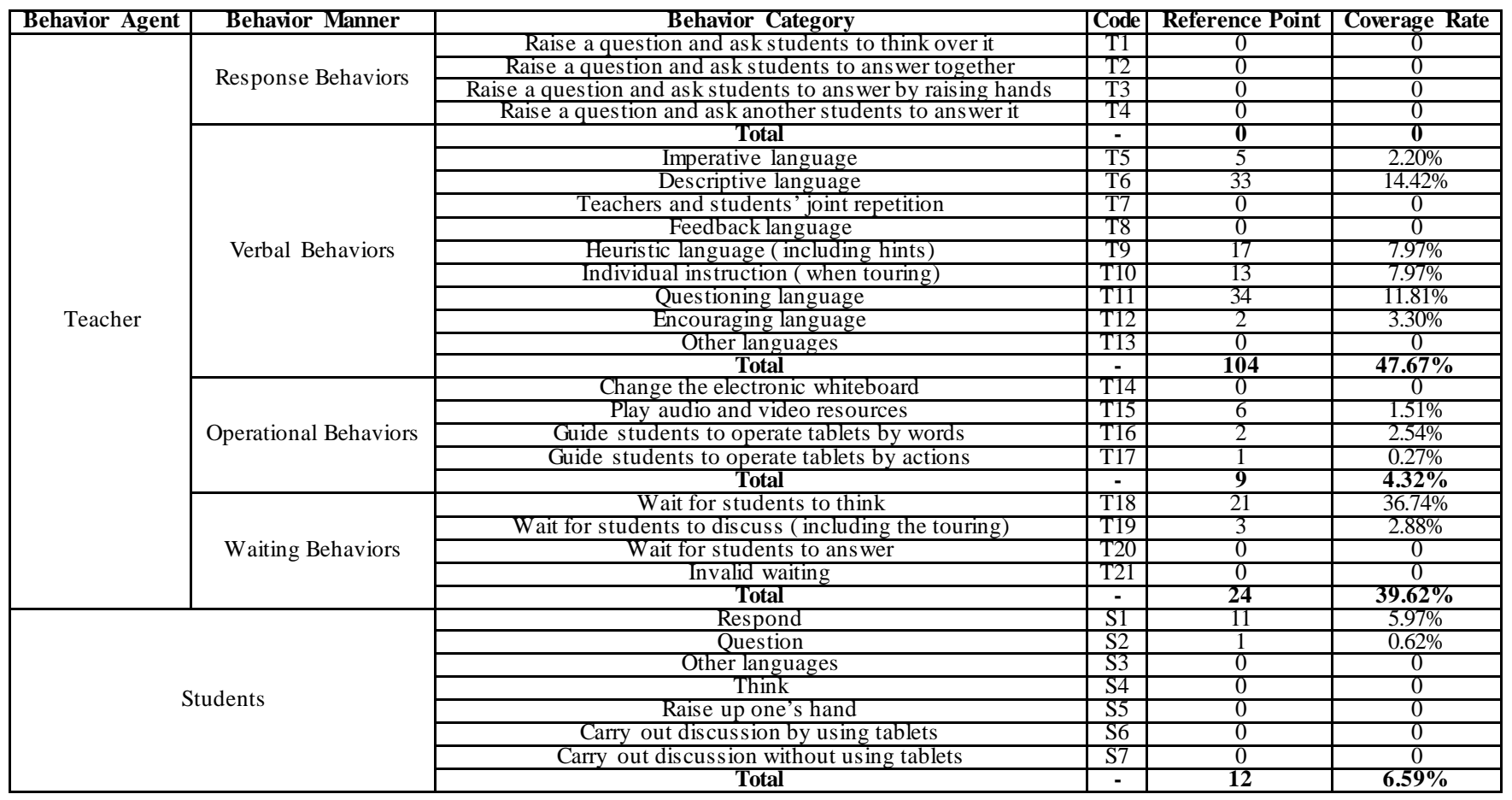


teachers' behaviors in detail so that we can observe the influence of the teacher on learners in the smart classroom. The influence is very important not just for verbal behaviors and response behaviors, but also for operational behaviors. Moreover, some operational behaviors indicate that the teacher consciously use the interactive media for guiding learners to learn. In the overall behavioral structure, a set of class teaching strategies are gradually formed with the guidance by the teacher's descriptive language and the promotion by questioning language, driving students' active learning by the operational behaviors of interactive media and providing sufficient time for students' thinking and discussion. This is de facto a problem-driven or task-driven learning.

\section{CONCLUSIONS AND IMPLICATIONS}

In Fig. 1, through the statistics of behavior reference points, it can be found that in a smart classroom supported by interactive media, there are the most reference points, namely 34 for the teacher's "questioning language" behavior, followed by 33 reference points for the "descriptive language" behavior and 21 reference points for the "wait for students to think" behavior. In observed behaviors, the least reference point can be found for the teacher's "guide students to operate tablets by actions" behavior and the students' "question" behavior, only 1; followed by 2 references points for the teacher's "guide students to operate tablets by words" behavior and "encouraging language" behavior.

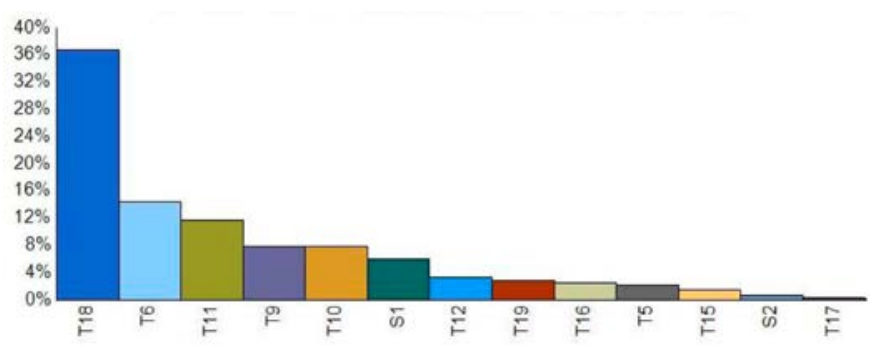

Fig. 2. Behavior Coverage Rates

In Fig. 2, through the statistics of the behavior coverage rates, in a smart classroom supported by interactive media, the highest coverage rate of $36.74 \%$ can be found for the teacher's "wait for students to think" behavior; followed by $14.42 \%$ for the "descriptive language" behavior and $11.81 \%$ for the "questioning language" behavior. In observed behaviors, the least coverage rate can be found for the teacher's "guide students to operate tablets by actions" behavior, being $0.27 \%$; followed by $0.62 \%$ for the students" "question" behavior and $1.51 \%$ for the teacher's "play audio and video resources" behavior.

In terms of behavior manner, verbal behaviors are the primary manner with a coverage rate of $47.67 \%$ and 109 reference points, followed by the coverage rate of $39.62 \%$ and 24 reference points for waiting behaviors. Then the students' behaviors have the coverage rate of $6.59 \%$ and 12 reference points. Lastly, the operational behaviors have the coverage rate of $4.32 \%$ and 9 reference points. Based on the above results, from the perspective of qualitative analysis, it is found that there are differences between behaviors of teachers and students in the smart classroom and those in a traditional multimedia classroom. The checklist makes a division of
The research found that the smart classroom supported by interactive media was more learner-centric than the traditional multimedia classroom. Compared with the traditional standardized knowledge output and homogenization of education and teaching, the smart classroom under the support of interactive media offers unlimited possibility for learners to exploit their potential. For example, learners can fully carry out the individualized learning around learning resources, and discover, establish and form obvious individual learning styles and ideas. The classroom organization can be developed in a socialized way and learners can make full use of their personal strengths for cooperative and open learning.

In the smart classroom, the interactive media technologies provide the basis for creating a harmonious learning environment. The introduction and reasonable use of interactive media is the key to realizing effective learning. According to this research, in an interactive media supported smart classroom, learners' learning is influenced by factors: first, the interactivity, quantity and carrying capacity of knowledge of the interactive media; second, the teacher's personal behaviors and teaching style. When the interactive media is highly interactive and can effectively transit and cover learning resources, learners' learning is dependent on technology tools, so they can be harmoniously and autonomously integrated into the human-computer interaction environment, open up their mind and accept knowledge efficiently. When the interactive media becomes a passive medium for transmitting teaching information (in a situation that the use of it is confused or less interactive), the learners' learning effects mainly rely on teachers' individual qualities. In this case, traditional teaching patterns are more likely to happen, such as "the teacher dominating the classroom" and "cramming". Then, the teaching information is transmitted unidirectionally with a low teaching efficiency and lack of capacity building.

Therefore, the smart classroom should be a kind of learning mode which is based on the interactive media technology, centers on teaching resources and must be teacher-guided and students-centered and aim to solve problems and cultivate students' advanced thinking ability. It should be active and open learning with distinctive personal learning style. However, in a smart classroom supported by interactive media, the teaching situation imposes higher requirements for students' autonomous learning abilities and 
makes it more difficult for teachers to undertake the learning assessment. Further researches are still required on how to design an adaptive learning system under the support of interactive media and centering on active learning of learners, and how to feedback and assess teaching promptly based on collection and processing of learning data.

\section{REFERENCES}

[1] Huang Ronghuai, Hu Yongbin, Yang Junfeng, Xiao Guangdei. The functions of smart classroom in s mart learning age [J]. Open Education Research,2012,(02):22-27.

[2] He Kekang. Wisdom Classroom + Class teaching Structure Reform-The Fundamental Methods of Realizing Educational Informationization [J] Educational Research, 2015,(11):76-81+90.

[3] Huang Ronghuai, Yang Junfeng, Hu Yongbin. From Digital to Smart: The Evolution and Trends of Learning Environment [J]. Open Education Research,2012,(01):75-84.

[4] Xia Jiafa. The design of teaching activities [M]. Wuhan: Central China Normal University Press, 2010: 5.

[5] Zhang Jianqiong. Teaching theory meaning of Teaching Behavior Research [J]. Theory and Practice of Education,2004,(17):50-53.

[6] $\mathrm{Mu} \mathrm{Su}$, ZuoPingping. Research on class teaching behavior analysis methods in informationized teaching environment [J]. e-Education Research, 2015,(09):62-69.
[7] $\mathrm{Mu} \mathrm{Su}$, ZuoPingping. Research on class teaching behavior analysis methods in informationized teaching environment [J]. e-Education Research, 2015,(09):62-69.

[8] Han Hou, Wang Dongqing, Cao Chang. Analysis and research on interactive behaviors of class teaching in a 1:1 digital environment. eEducation Research,2015,(05):89-95.

[9] Wang Xiaochen, Jiang Shaoxiang, Huang Ronghuai. A study of interaction observation tools in primary and middle schools for wisdom classrooms[J]. e-Education Research,2015,(09):49-53.

[10] Wang Xiaochen, Huang Ronghuai, Wang Mengshu, Lu Tingting. Analysis of classroom interaction in smart classroom in primary and middle schools [J]. e-Education Research,2016,(12):111-116.

[11] Zhang Yi, Zhu Yuan, Bai Yuqing, Li Xiaoyan, Zhu Yinghui. Research of the interaction behavior characteristics of primary mathematics in the smart classroom [J]. e-Education Research,2016,(06):43-48+64.

[12] Chen Di. Research on the classroom instruction under the support of interactive media[D]. Central China Normal University. 2012.

[13] Ye Lijun. A comparative study of mathematics teachers' class teaching behavior [D]. Nanjing: Nanjing Normal University. 2011.

[14] Guo You. Teacher teaching skills [M]. Beijing: Capital Normal University Press. 1993: 229.

[15] Xiao Feng. Interactive analysis of classroom speech act [J]. Journal Liaoning Normal University, 2000, 23(6):40-44.

[16] Ye Lijun. A comparative study of mathematics teachers' class teaching behavior [D]. Nanjing: Nanjing Normal University. 2011. 